\title{
Stress Corrosion Cracking and Copper Alloy Products
}

\author{
Vladivoj Očenášek (0000-0002-7817-8701), Jan Luštinec (0000-0001-8764-6514) \\ SVÚM a. s., Tovární 2053, 25088 Čelákovice. Czech Republic. E-mail: ocenasek@svum.cz, lustinec@svum.cz
}

Stress corrosion cracking (SCC) is a common cause of structural failure. The simultaneous action of the corrosive environment and tensile stresses creates cracks that have an intercrystalline or transcrystalline character. These are cracks with a fragile morphology of the fracture surface without signs of plastic deformation in their vicinity. SCC cracks occur in several alloys. This paper focuses on copper alloys in which this type of failure occurs frequently. Examples from practice show cases where the occurrence of SCC violation was related to the conditions of use of components and their production technologies. The paper does not aim to capture all the influences associated with the occurrence of SCC failure of copper alloy products.

Keywords: SCC stress corrosion cracking, Copper alloys, Cold deformation, Heat treatment, Tensile stress, Residual stress

\section{Introduction}

Stress corrosion cracking (SCC) is one of the forms of breaking materials. This type of failure often leads to unexpected and sudden fractures. Cracks form and propagate always occur in a corrosive environment in the presence of tensile stresses. SCC violation is thus due to the interaction of these two factors. Another characteristic feature of SCC failure is imperceptible manifestations on the surface at the crack site. There are no corrosion products on the surface and no traces of plastic deformation are visible around the crack. The absence of plastic deformation is due to the fact that cracks occur at stresses lower than the yield strength. SCC failure occurs at various combinations of chemical composition of the material, the state of the structure of the material, the state of the surface, the composition of the ambient atmosphere, temperature, and mechanical stress. Due to the emergence of SCC violations, different combinations of these factors lead to a relatively large variance of results and to their difficult predictability. For a particular metal or alloy, there are then typical environments that cause SCC failure. Therefore, in the case of long-term exposure to stress and the environment, a change in the chemical composition of the environment over time may also play a role. Because failure of a structure or part due to SCC occurs at low stress levels, cracks can occur over a wide period, depending on the interaction of the individual factors. It can be tens of hours or many years. SCC fractures have a brittle fracture morphology and can be intercrystalline or transcrystalline. In many cases, these are mixed quarries, which have both transcrystalline and intercrystalline character (Fig. 1). Often the crack branches away from the main crack. The formation and propagation of SCC cracks can be influenced by other factors related to the production technology and the type of alloy. These are, for example, phase changes, the occurrence of intermetallic phases or precipitation processes.

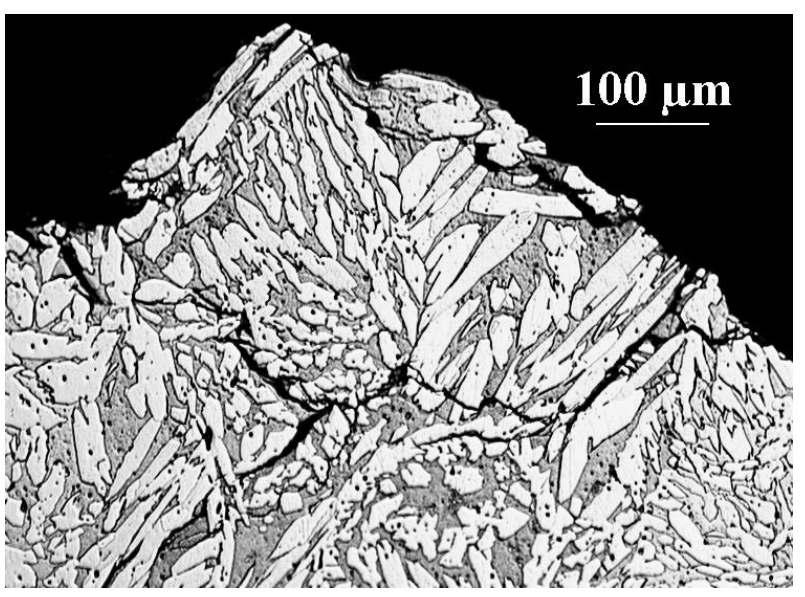

Fig. 1 Partly intergranular and transgranular SCC crack of two-phase (a/ $\beta$ ) brass CuZn40Pb2 [10]

The place of occurrence of SCC cracks is usually surface defects from machining, handling, local corrosion attack, inclusions, dealloying, structural notches or it can be fatigue cracks. The severity of these sources of SCC cracks is then determined by the magnitude of the stress (inserted or residual) and the notching effect of the initial defect or structural notch. The occurrence of SCC cracks can be found both in steels $[1,2]$ and in alloys of non-ferrous metals $[3,4$, 5]. SCC violation cannot be completely ruled out for pure metals, such as pure copper or pure iron [6]. Copper alloys are a frequent subject of interest [7, 8]. The mechanism of formation and propagation of SCC cracks depends on both the environment and the composition of the material. Several models have been 
proposed for SCC failure of metallic materials that bind to pure metals or alloys of non-ferrous metals and steels. The best known are models based on dissolution, adsorption and hydrogen embrittlement. The most frequently mentioned mechanism for a number of metallic materials is the film-induced cleavage mechanism, in which a brittle nanolayer is formed around the crack root. Detailed information on these models is given, for example, in $[6,7,9]$.

This paper is devoted to the occurrence of SCC cracks in copper alloys. SCC failure is most often encountered in brass with a higher $\mathrm{Zn}$ content. Typical examples are machinable brasses, with a $\mathrm{Zn}$ content of about $40 \%$. Brass with a $\mathrm{Zn}$ content lower than $15 \%$ practically does not suffer from SCC failure. Copper alloys in which we encounter SCC failure also include brasses containing $\mathrm{Ni}$ or aluminum bronze. If we do not consider pure copper, then the least sensitive alloys are $\mathrm{Cu}-\mathrm{Ni}$ binary alloys.

The aim of the paper is to show the influence of stress, production technology and the conditions of use on SCC cracking of selected products. The examples do not specify a corrosive environment. It was always a normal atmosphere of the outdoor environment or the environment during storage or production of the part. For this reason, possible mechanisms of SCC crack formation and propagation are not discussed. The conclusions proving that these are SCC cracks were made on the basis of information on the production technology, mechanical stress of the part, the results of metallographic analysis, hardness measurements and the characteristics of SCC cracks.

\section{Sources of stress}

The prevention of the formation of SCC cracks consists mainly in the choice of a suitable material for the given environment and in the choice of technological parameters of production, especially heat treatment and cold deformation. An important role is played not only by the tension in which the parts are used, but also by the history that precedes the use of the part. Stresses can be residual from production or introduced by assembly or operating loads. Underestimation of the influence of the interaction of production technology (residual stresses), operating conditions (applied stresses), design influences and corrosive environment can lead to unexpected operational failures of individual parts or loss of function of the entire structure. Therefore, most cases of SCC violation are always a combination of the influence of a number of factors. The unexpectedness of the occurrence of SCC cracks usually lies in the fact that the applied stresses are much lower than those corresponding to the minimum values determined by static strength calculations.

\subsection{Cold deformation}

Depending on the stress level (whether residual or applied), the corrosive environment determines the formation of SCC cracks. The first mentions of SSC in copper alloys are from the second half of the nineteenth century, when under the influence of a specific external environment, the ammunition deteriorated by cracking the cartridge case (Fig. 2). This form of SCC violation was called season cracking. The name comes from the end of the 19th century, when ammunition was stored in stables during the monsoon rains in India until the dry season. Due to the internal stresses in the cartridge case (after cold deformation in the manufacture of the cartridge case and superposition with the stress introduced into the cartridge case by inserting the cartridge) and ammonia from horse urine, most cartridges corroded and cracked. Annealing to remove internal stresses in the manufacture of cartridges has eliminated this problem. Similarly, in the case of cold-drawn bars, cracks can occur when stored in an unsuitable environment. Fig. 3 shows a case of a cold drawn rod made of nickel brass CuZnNi18 stored near a sanitary facility [10]. In the case where the influence of the corrosive environment can be expected and where there are residual tensile stresses on the surface in the product, and it is also possible to consider the applied or operating stress, annealing must be used to remove internal stresses. The annealing temperature for the removal of residual stresses in copper alloys is around $300{ }^{\circ} \mathrm{C}$.

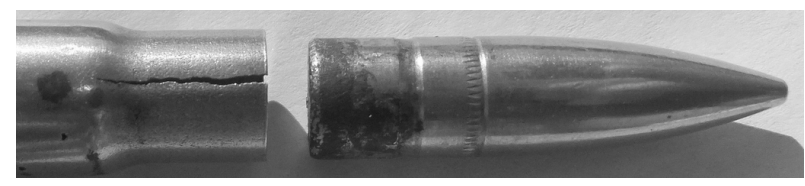

Fig. 2 Season cracking of the brass cartridge casing [11]

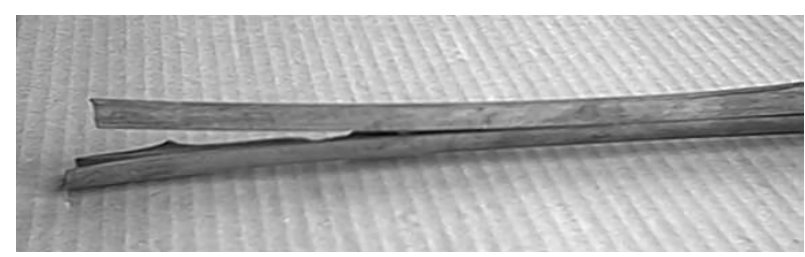

Fig. 3 SCC cracks of cold drawn CuZn20Ni18 bar due to improper storage [10]

The occurrence of SCC cracks due to residual stresses after cold deformation may also be related to ancillary technological operations, such as the division of bars or thick-walled pipes. If they are separated after hot extrusion until the material has cooled, local surface plastic deformation may occur at the cut surface, which may be a source of problems by following cold drawing. When calibrating the dimensions of bars by cold drawing, for larger cross-sections, pushing the 
bar into the die is used. When pushing, the beginning of the rod at the exit of the die is stressed by tensile stress. If a sufficiently long time elapses between the division of the bars and the pushing into the die, a SCC crack will form at the face of the bar and the bar will rupture at the exit of the die (Fig. 4). The course of the deformation of the surface layer caused by the division of the rod and the SCC crack adapted to the shape and orientation are very clearly visible in Fig. 5. These cracks, when pushed into the die, are the site of extensive and fatal failure of the rod by longitudinal cracks (Fig. 4). On the fracture surface (Figs. 6 to 9), the initiating part of the SCC crack and the crack, which is formed only when pushed into the die, is then very clearly visible. This example shows that a completely marginal technological operation can lead to production interruptions, but the detection of the cause is not easy and instant? [10].

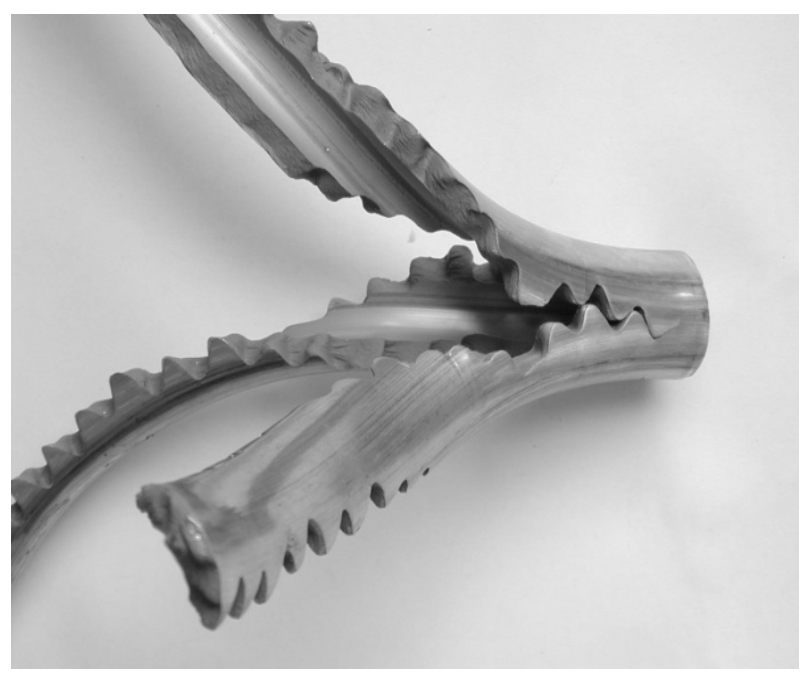

Fig. 4 Fatal cracks after pushing the brass tube before drawing initiated by small SCC cracks [10]

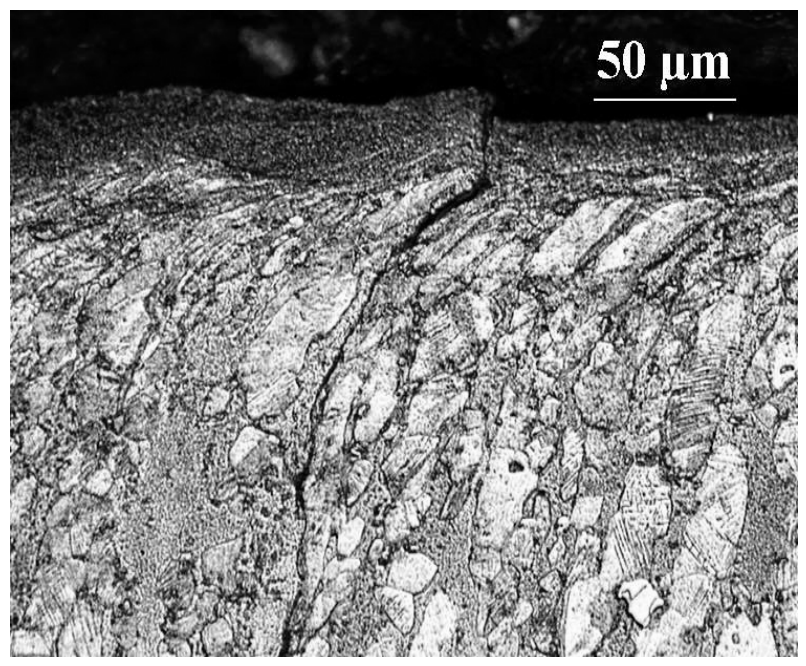

Fig. 5 SCC crack in the deforrmad surface layer after cuting the rod [10]

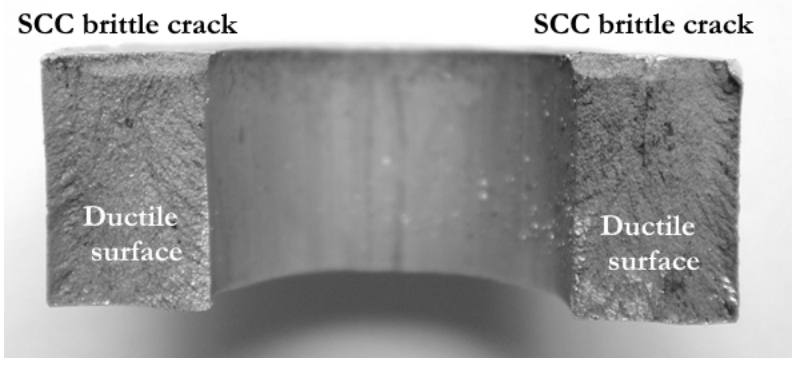

Fig. 6 SCC initial cracks at the surface of the cut cross section [10]

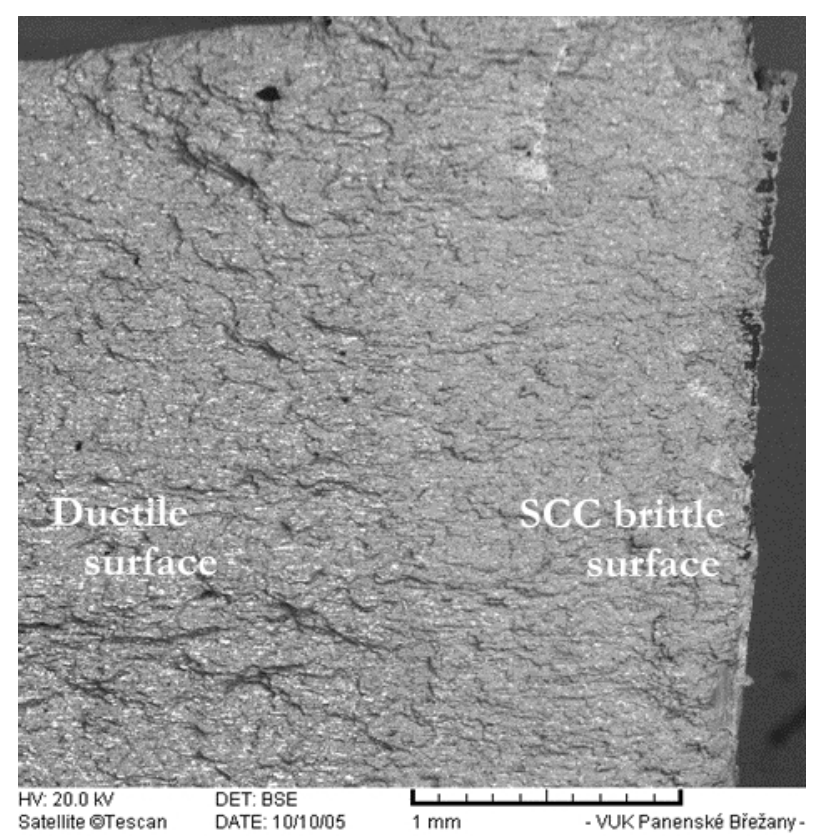

Fig. 7 Overall view of the crack, which consists of the brittle part of the SCC fracture at the surface and the continuing $d u$ ctile fracture [10]

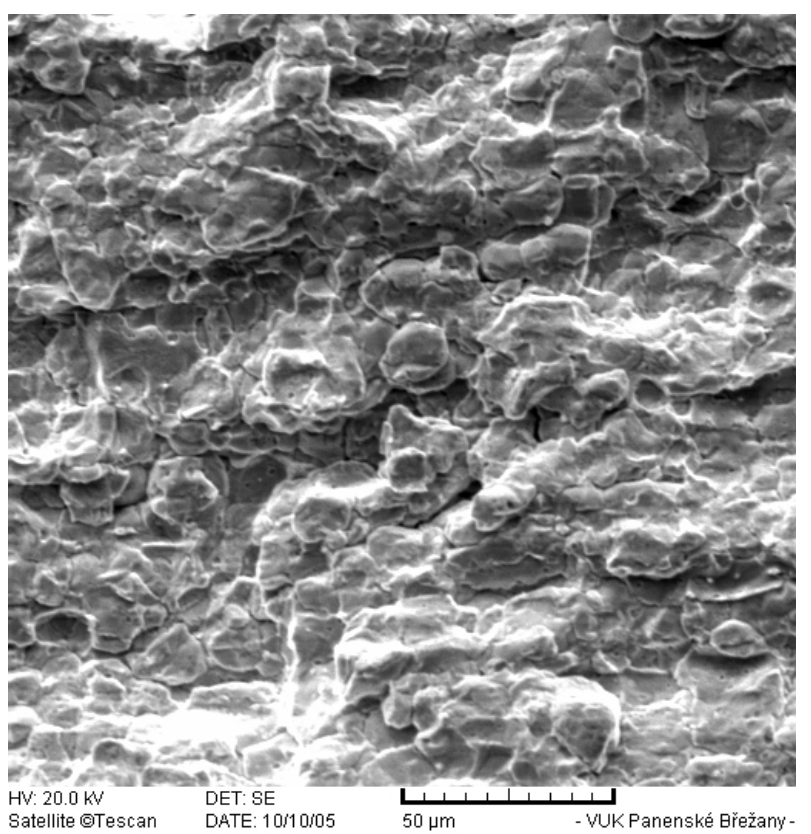

Fig. 8 SCC brittle part of the crack [10] 


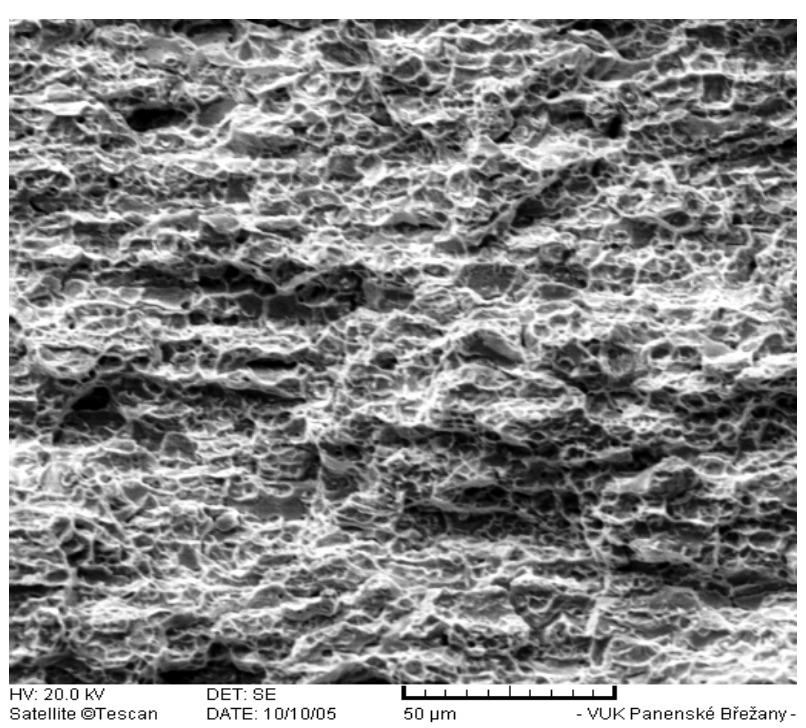

Fig. 9 Ductile part of the crack related to the SCC initial crack [10]

\subsection{Heat treatment}

As opposed to the aluminum alloys, the occurrence of SCC cracks in copper alloys due to heat treatment of precipitation hardenable alloys is a relatively rare phenomenon. The cause is residual stresses that arise during cooling from the solution annealing temperature. Unlike tensile residual stresses after cold drawing, the residual stresses on the surface after rapid cooling are compressive. Compressive stresses are not dangerous from the point of view of SCC failure. However, under certain circumstances, an SCC violation may occur. An example is a low-alloyed age hardenable $\mathrm{Cu}-$ $\mathrm{CrZr}$ alloy. In Fig. 10 is a hot extruded T-profile, which has been machined to its final shape before soldering the contacts after heat treatment. After some time after machining and soldering the contacts, a crack appeared on the surface on both sides along the whole part (Fig. 11). It was an intercrystalline network of SCC cracks (Fig. 12). After cooling from the solution annealing temperature, compressive stresses remained in the profile on the surface. However, due to the removal of the material, part of the profile was redistributed so that there were tensile stresses on the surface, which was the cause of SCC cracks. To prevent the formation of SCC cracks, it is necessary to choose the procedure during heat treatment so that residual stresses are removed or minimized [10].

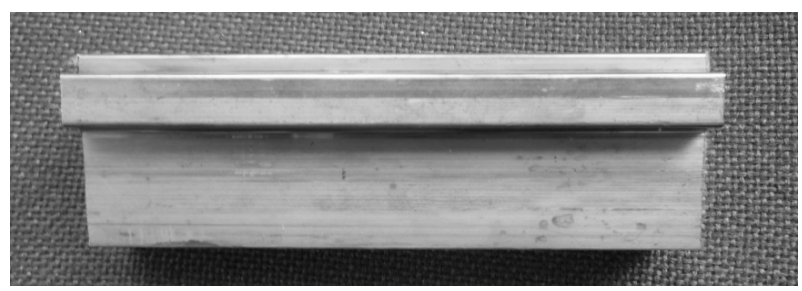

Fig. 10 T-profile from CuCrZr alloy before beat treatment and machining [10]

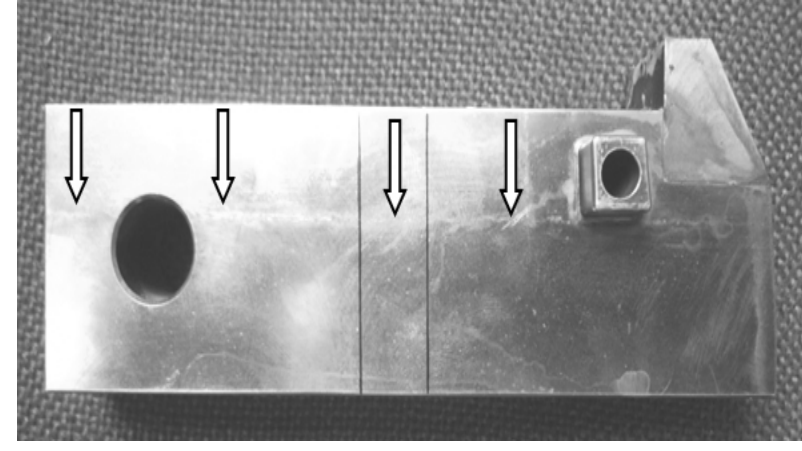

Fig. 11 Position of the SCC crack in the T-profile after heat treatment.and machining with marked position for crack. metallography [10]

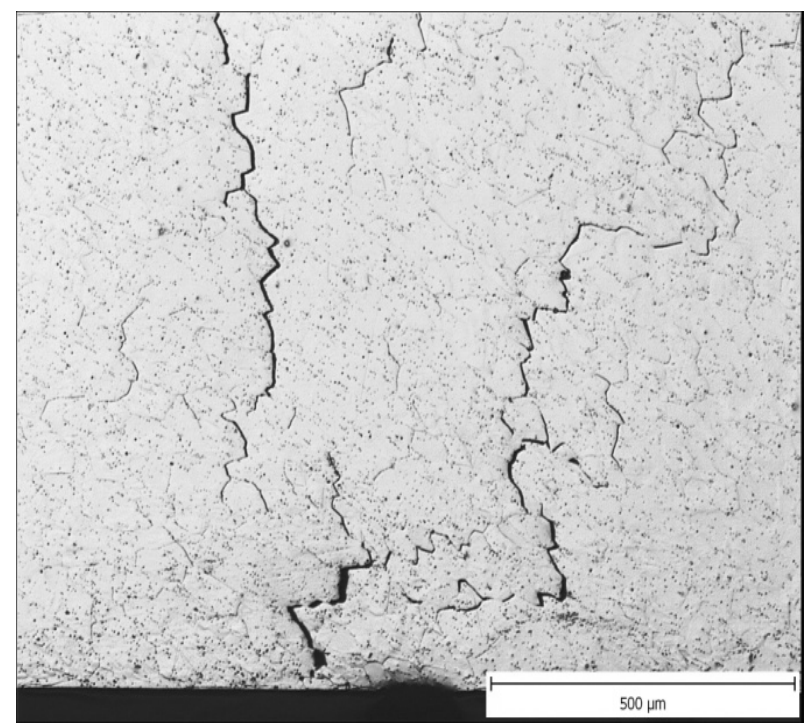

Fig. 12 Intercrystalline SCC crack in the T-profile after heat treatment and machining (Fig. 10) [10]

\subsection{Assembly and operational stress}

A typical and very common case of SCC cracks are fittings made of hexagonal bars from machinable brass with a higher $\mathrm{Zn}$ content $(\mathrm{CuZn} 40 \mathrm{~Pb} 2)$. The bars are cold drawn to the required dimensional tolerances after hot extrusion. After cold drawing, tensile stresses remain on the surface. During machining, they are usually redistributed. In combination with the stress applied to the fitting during assembly, SCC cracks then form, usually in the thin threaded part of the fitting (Fig. 13 and 14). The applied stresses during assembly can be caused by excessive tightening or by a larger volume of sealing material in the thread. The effect of the deformation during the cold calibration drawing on the uneven hardness along the cross section of the hexagonal rod is evident in Fig. 15. This figure shows how the course of hardness changes due to drawing and heat treatment. The preventive measure against the occurrence of SCC cracks is annealing to remove the internal stresses of the cold-drawn rods and to observe the specified conditions during the assembly of the fitting. 


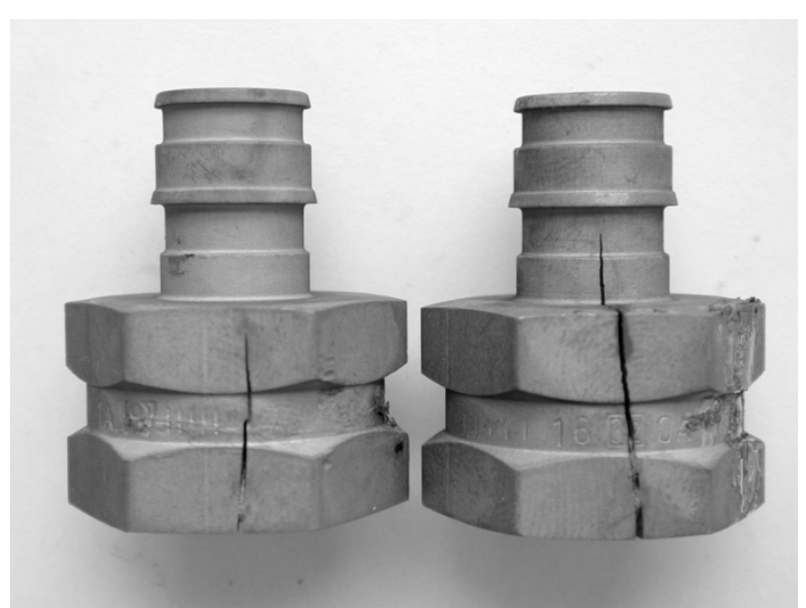

Fig. 13 SCC cracks of CuZn40Pb2 fittings due residual, assembly, and operating stresses [10]

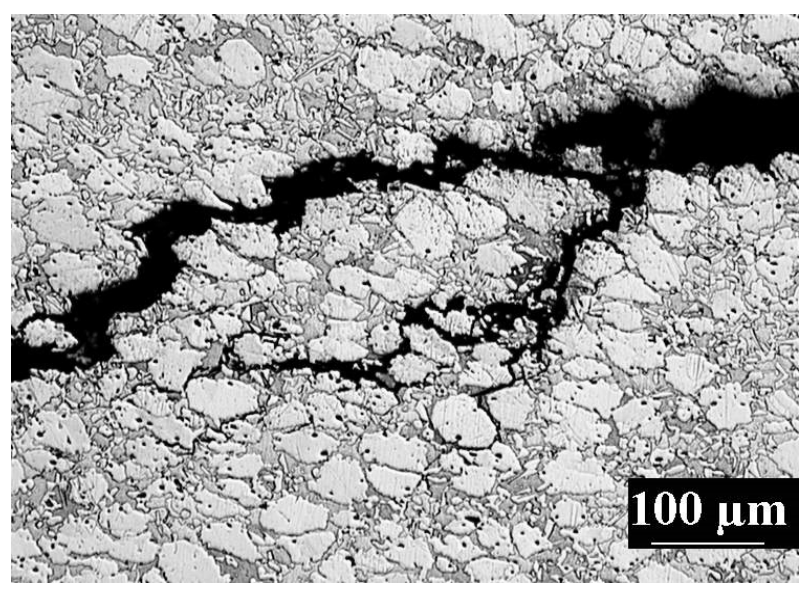

Fig. 14 Intergranular SCC crack in the brass fitting [10]

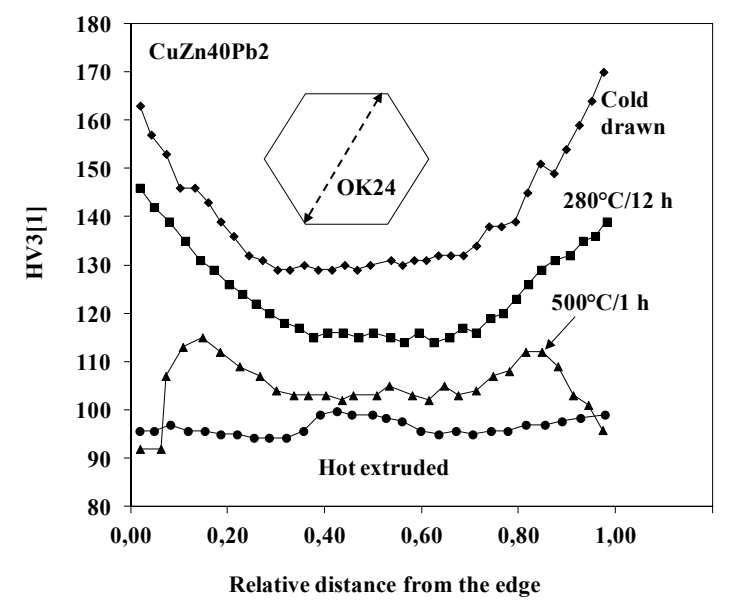

Fig. 15 Influence of cold drawing and heat treatment on hardness of $24 \mathrm{~mm}$ brass hexagon bar (CuZn40Pb2 alloy) [10]

Another case of the formation of SCC cracks, which were caused by the stresses applied during assembly, are brass clamps made of CuZn40Pb2 alloy. Clamps were used for fastening tram overhead contact line. As the clamps were not tightened with a torque wrench during the assembly, they gradually began to crack under the assembly and operating stresses. The
SCC crack was caused by the notch effect in the groove of the clamp for fixing the overhead line. (Fig. 16). In the case of the static strength test of the clamp, the fracture occurs at the same location of the clamp, but with large plastic deformations at the fracture location (Fig. 17). The absence of plastic deformation around the crack thus confirmed that it is an SCC failure [10]. To avoid the formation of SCC cracks in operating conditions, it is therefore necessary to optimize the assembly forces.

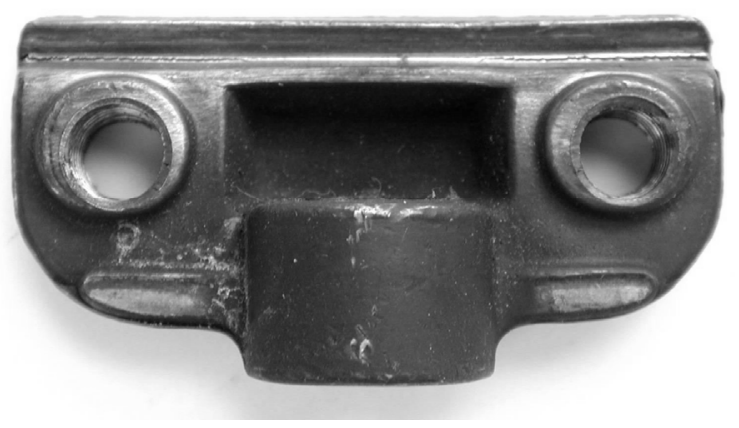

Fig 16 Due to assembly and operating stresses visible SCC crack in the groove of the CuZn40Pb2 clamp [10]

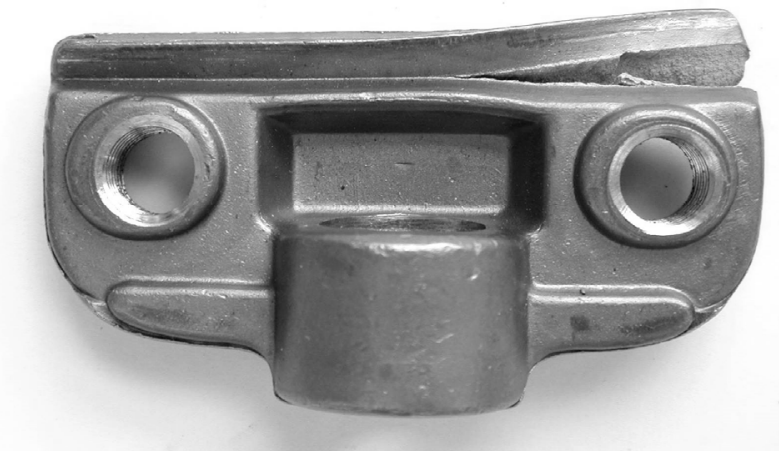

Fig. 17 Crack of the CuZn40Pb2 clamp after static loading [10]

\section{Conclusion}

The examples of SCC cracks of copper alloy components in the paper characterize typical and atypical cases of cracking, which lead to their fatal failure. To prevent this type of failure, it is necessary not only to choose a suitable type of alloy for the given corrosive environment but also to consider both the influence of production technology and assembly conditions.

\section{Acknowledgement}

The paper presents the results that were achieved within the projects FA - EV 064/98 "Increasing the utility properties of non-ferrous metal products and their alloys", FI-IM2/098 "Research of technology straightening and drawing of cooperalloys bars with enhanced shape and size accuracy" and FI-IM3/072“. Development of manufacturing technology of $\mathrm{Cu}-\mathrm{Ni}$ condenser tubes 
for the power industry and rods from special copper alloys for automotive and mechanical engineering applications".

\section{References}

[1] MOHTADI-BONAB, M.A. (2019). Effects of Different Parameters on Initiation and Propagation of Stress Corrosion Cracks in Pipeline Steels: A Review. In: Metals, Vol. 9, No. 5. ISSN 2075-4701.

[2] ZATKALÍKOVÁ, V., MARKOVIČOVÁ, L., CHALUPOVÁ, M. (2016). Corrosion resistance of Cr-Ni-Mo Stainless Steel in Chloride and Fluoride Containing Environment. In: $\mathrm{Ma}$ nufacturing Technology, Vol. 16, No. 5, pp. 11931198.

[3] ARSENAULT, B., SIMARD, S., MARCOUX, P., GHALI, E. (2006). Stress Corrosion Cracking Mitigation of 7075-T6 Aluminum Alloy by Thermal Spray Coating. In. Paper presented at the CORROSION 2006, San Diego, California.

[4] CARTNER, J. L., HAGGARD, W. O., ONG, J. L., BUMGARDNER, J. D. (2008). Stress corrosion cracking of an aluminum alloy used in external fixation devices. In: Journal of biomedical materials research. Part B, Applied biomaterials, Vol. 86, No. 2, pp. 430-437.
[5] LUŠTINEC, J., OČENÁŠEK, V. (2019). Residual Stresses and Cracks in Forgings of Heattreatable Aluminium Alloys. In: Manufacturing Technology, Vol. 19, No. 4, pp. 637-643.

[6] RAJA, V. S., SHOJI, T. (2011). Stress corrosion cracking: Theory and practice, Woodhead $\mathrm{Pu}$ blishing Limited, UK. ISBN 978-1-84569-6733.

[7] HALL, I. D. (1977). Stress - corrosion cracking of copper - base alloys. Thesis for the degree of doctor of philosophy, The University of New South Wales School of metallurgy.

[8] KANNAN, B. M., SHUKLA, P.K. (2011). Stress corrosion cracking (SCC) of copper and copper-based alloys. In: Stress corrosion cracking: Theory and practice, pp. 409 - 426. Woodhead Publishing Limited, UK. ISBN 978-1-84569-6733.

[9] JONES, R. H., RICKER, R. E. (1992). StressCorrosion Cracking Materials Performance and Evaluation. ASM International. ISBN 0871704412.

[10] OČENÁŠEK, V., LUŠTINEC, J. Unpublished results.

[11] https:// forum.cartridgecollectors.org/t/ammo-deterioration/40790/6 